\title{
Does Purity Arise from the Taint of Impurity?
}

\section{Kenryo MinOwA}

Introduction. The debate is referred to as 'lou sheng wu lou zheng lun' meaning 'does purity arise from the taint of impurity'. In this small treatise the debate between Rev. Fa-Bao (?-650-?) and Hui-Zhao (650714) regarding this problem will be briefly discussed. Additionally, the same debate occurred in Japan between Rev. Saicho (767-822, of the Tendai School) and Tokuichi (749-824, of the Hosso School) as reported in the 'Shugo-kokkaisho' will be discussed.

I. Rev. Fa-Bao wrote two texts called 'ye sheng bo xing quan shi lun' and 'yi sheng bo xing jiu jing lun' ('jiu jing lun') which asserted the idea that all living beings had the buddha-nature. But even if we concede this idea, one question still remained. That is, positively saying, What is the original cause of the first realization at the first stage of the path of insight. In the understanding of the founder of Fa-xiang school, Ji (632-682), the first undefiled wisdom would be attained by the seed having the nature of purity which originally and naturally existed. It meant the seed having the nature of purity was the very cause of the undefiled wisdom.

According to this concept Fa-xiang school divided living beings into two types, one was those who had such a seed originally and the other was those who did not have it. This became a traditional and authoritative concept in the Fa-xiang school later, but Rev. Fa-Bao did not support this concept. He said in the 'jiu jing lun', which was believed to be missing for a long time, but was found in the Ishiyamadera temple in 1986 by Japanese Buddhist scholar (Asada [1986a] [1986 b]). This text consists of six Volumes. The eighth chapter of the forth vol. said:

With the undefiled teaching we can let the impression of listening appear. This impression of listening differs from the defilment. It makes the prior defilement fade away gradually and make the undefilement appear gradually on the following 
moment. (Line No. 461-467 vol. 4)

Rev. Fa-Bao insisted that although he said that the impurity appeared in the defiled condition, it did not mean that there was the defiled seed having the nature of the impure. He quoted ' $D a z h i d u$ lun' and ' $y u$ qie lun' to support this understanding (Line No. 467-472 Vol. 4). He emphasized that the pure was made born by the impression of listening to the pure Buddha's sermon. He said:

With the impression of listening to the Buddha's sermon, making it the cause of the undefilement, saint path can put in an appearance. No sutra says that there is the conditional undefilement in the defilement and making it the original cause, saint path can put in an appearance. (Line No. 467-477 vol. 4)

This comment is important because he is attentive to maintaining a general rule that cause and reward should be in the same category. Even though he is careful in this general rule, we can not help acknowledging that he is standing on the experimental field and that the cause of the first purity is still unclear in his view.

Rev. Hui-Zhao put his finger on this logical weakness and this is the point of this dispute. He told $F a$-Bao to make clear the original cause of the first purity. Rev. $F a-B a o$ replied;

Why do you not believe 'nie pan jing' says ignorance changes into wisdom? (Line No. 510 Vol. 4)

Rev. $\mathrm{Fa}$-Bao argued this subject as the matter of the belief quoting 'nie pan jing'. This indicates that it seemed difficult for him to keep the logical connection with this subject. He said that the purity was not born from the defilement at the beginning, but here he said that ignorance changes into wisdom. What does this mean? Unless the meaning of "change" is made clear, his view will result in the thought that the purity is born from the defilement. But he did not explain this topic in detail.

II. Rev. Hui-Zhao made objections to his view in his treatise 'neng xian zhong bian hui ri lun' ('hui ri lun'). In the seventh chapter of second Vol. of this writing he quoted the sentences of 'jiu jin lun' and criticized (Taisho Vol. 45 p. 430c. 1l.3-5). His opinion is admitting the existence of both natural dharma and conditional dharma and he said that the first 
wisdom of thefirst stage of enlightenment is attained by the seed having the nature of the undefiled, which is called the natural and original seed having the nature of purity. Moreover he said:

The seed before the first realization at the first stage is defiled, if the seed is defiled, it could never bear the undefiled dharma. Highest mundane dharma is the worldly seed and is not the non-worldly seed which bear the purity. (Taisho Vol. 45 p. 430 c $l l .14-15)$

He emphasized that the seed of the impurity never became the original cause of the purity. It may be said that he was very attentive in keeping a general rule that both the nature of cause and that of reward should belong to the same category. He quoted 'she da sheng lun' and 'yu qie lun' mainly, which were translated by Xuan-Zang, and insisted that there was an original and natural seed according to ' $y u$ qie lun' but it is obvious that the sentence of ' $y u$ qie lun' was coming from the record quoted in second Vol. of 'cheng wei shi lun' and we can not find it in the original text. Anyway Rev. Hui-Zhao never admitted that the reward of the impure arose from the seed of the impure and kept strictly the general rule.

III. Now we will examine the case of the Japanese Buddhists, as Saicho and Tokuichi. These two monks are famous for debating each other in the Early Heian Period and we can examine the same subject in Saicho's writing. This subject is addressed in the fifth chapter, which is called 'hyo uro sho muro so sho', of three-second Vol. of 'shugo-kokkaisho'.

Tokuichi interpreted ' $y u$ qie lun' and it was remarkable in expressing essence of the dispute. The wisdom of the first stage of realization could not be attained if all the seeds belonged to the newly and acquired ones. The main reason was that a general rule could not be kept in case of this. If we want strictly to keep this rule, it is enough to admit to the natural and original seed, so we can say this view is rational from the logical view point.

In the quotation of the Tokuichi there were several sentences of "jiu jin lun' which were introduced as a saying of an old person (Taisho Vol. 74 226a. 1. 27-b. 1. 10). Of course we can identify him as Rev. Fa-Bao, and 
the sentences corresponded to those lines of No. 476-477, 489-492, 495-494 of the fourth Vol. of ' $j i u$ jin lun' and his opinion was suggesting that he could say that the purity was born from the impurity.

Tokuichi criticized these sentences as they were not so because most of them were guesses and there was little evidence. (Taisho Vol. 74 226b. 11. 10-11) Toku-itsu said if he might admit that the reward of listening to the Buddha's sermon, which was defiled, became the cause of the first wisdom or realization of the first stage, a new problem would occur. That was, whether its reward had influence on the seed of defilement or of the undefilement. He said there were mistakes in both cases.

If it had influence on the seed of the defilement, then it would invite a mistake. It never became the cause of the first wisdom of the first stage because' ' $y u$ gie lun' said it did not coincide with reason to admit that supraworldly dharma was born from the seed whose nature was rough and heavy (Taisho Vol. 30 589a. 11. 14-16). If it had influence on the seed of undefilement, then it would invite two mistakes. One was differing from Buddha's sermon and the other was matching a non-Buddhist teaching because it deviated from a general rule that cause and reward should belong to same category.

Now we can acknowledge Tokuichi's point of view was in the same category. But I have already quoted that $\mathrm{Fa}$-Bao's sentence which indicatep that he was also careful in keeping this rule. As a consequence it is recognized that both are careful for keeping the same category. The difference between the two was as follows; $F a$-Bao admitted the purity would be born in the condition of the impurity gradually according to the Buddha's sermon which is pure and the first wisdom or realization of the first stage was the reward of the undefiled Buddha's teaching.

Tockuichi did not admit this view. He criticized this as mistake because it ignored the difference between the impurity of a subjective speaker and that of a subjective listener.

He thought it was difficult to understand this view before the first stage of realization because the natural and original seed was subtle and it did 
Does Purity Arise from the Taint of Impurity? (K. MINowA)

not take a reward before that stage. We can conjecture that this view is under the influence of ' $y u$ qie lun'. This argument finished with a comment of Saicho. He made a criticism.

V. Saicho criticized both views as imperfect.

Both views seem to have reason but they do not reach the right understanding. Why they do not reach? Because Fa-Bao did not support the ultimate reality which is following conditions. Because there still remains store-consciousness which is born and unborn. Because he still has an attachment to the Three Vehicles and support the seed. Bacause he follows a method which has only partial meaning. Because Toku-itsu does not support the nature of the ten realms' of living beings which are following condition. Because he has an attachment to the natural seed which is misunderstanding. Because he mistakes the three undefilement of ' $y u$ qie lun'. Because he does not unders. (Taisho Vol. 74. 227a. 28-b. 4).

Saicho did not support both understandings. We can know from his opinion he was in the position that there was the ultimate reality which was following conditions. His saying indicates the seed of the ultimate reality was the most important for him. He thought the wisdom of the first stage of realization was attained by the seed of the ultimate reality. We can know that Saicho introduced the new idea in this dispute, as it concerns with the ultimate reality.

\footnotetext{
References

Asada [1986a] Masahiro ASADA; A Study of the First and Second Volumes of Ichijyobusshokukyoron by Hobo, Tho Ryukokudaigaku Ronshu No.429; The Journal of Ryukoku University, Dec. 1986, pp.75-99.

Asada [1986] Masahiro ASADA; A Study of the Fourth and Fifth Volumes of Ichijyobusshokukyron by Hobo, Bulletin of Institute of Buddhist Cultural Studies, Ryukoku University, No.25; Institute of Buddhist Cultural Studies, Ryukoku University, Kyoto, 1986, pp. 112-146.
}

$\langle$ Key Words〉 seed, purity, impurity, bija

(Research Fellow, The Eastern Institute) 